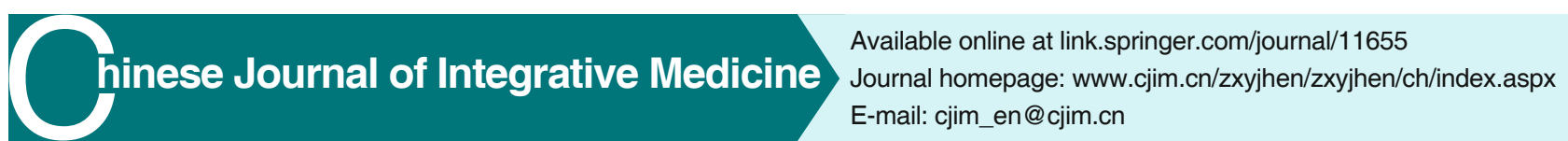

\title{
Perspective
}

\section{Reframing Palliative Care: An East-West Integrative Palliative Care Model}

\author{
S. Anjani D. Mattai ${ }^{1}$ and Ka-Kit P. Hui ${ }^{1,2}$
}

\begin{abstract}
Convergence of principles of palliative care and integrative medicine has led to the introduction of the new practice of integrative palliative care in which integrative therapies (including mind-body modalities, traditional Chinese medicine, Ayurveda, and dietary supplements) are used to provide symptom management for patients who are dying or experiencing the sequelae of serious illness and its treatment. We propose an East-West Integrative palliative care model using non-drug therapies, such as acupuncture, diet, exercise, and stress management that shift the paradigm from suppressing the symptoms of illness to addressing both the root cause of the symptoms and the imbalance and declining homeostatic reserve that perpetuate these symptoms. This whole-person model expands the reach of palliative care, prolonging a better quality of life and allowing the patient to maintain as many activities as possible by preventing symptoms and improving function. Through this approach we reframe the dialogue such that patients are "living better" rather than "dying better" when faced with serious illness or death. In this article, we provide an overview of the principles of palliative care, integrative medicine, and the novel area of integrative palliative care, and propose an East-West integrative palliative care model that incorporates and broadens the scope of these existing approaches.
\end{abstract}

KEYWORDS person-centered model, palliative care, integrative medicine, traditional Chinese medicine, acupuncture, symptom management, cost-effectiveness, reframing healthcare

\section{History of Palliative Care}

Palliative care is a relatively new discipline, and its founding is credited to Dame Cicely Saunders, an English nurse, social worker, and physician, who proposed a model of specialized care for the dying, and in 1967 went on to establish the first modern hospice, St Christopher's Hospice in London. Saunders also pioneered a fundamental principle of palliative carethe concept of "total pain"-that encapsulates the physical, emotional, social, and spiritual dimensions of pain. ${ }^{(1-3)}$ Since the 1960 's, palliative care has seen tremendous growth throughout the United States, becoming a recognized medical specialty in 2006. ${ }^{(4)}$ Recent data from America's Care of Serious Illness: 2019 State-by-State Report Card on Access to Palliative Care in US Hospital corroborates this expansion, indicating that $72 \%$ of U.S. hospitals with 50 or more beds have palliative care teams, an increase from $67 \%, 53 \%$, and $7 \%$ in 2015,2008 , and 2001, respectively. ${ }^{(5)}$

\section{Definition of Palliative Care}

Palliative care is defined by the World Health Organization (WHO) as "the prevention and relief of suffering of adult and paediatric patients and their families facing the problems associated with life-threatening illness. ${ }^{(5)}$ These problems include physical, psychological, social and spiritual suffering of patients and psychological, social and spiritual suffering of family members". ${ }^{(6)}$ The Centers for Medicare and Medicaid Services further specifies palliative care as a patient and family-centric model that fosters patient autonomy, through the optimization of "quality of life by anticipating, preventing, and treating suffering through addressing physical, intellectual, emotional, social, and spiritual needs, and facilitating patient autonomy, access to information, and choice". ${ }^{(7)}$

CThe Chinese Journal of Integrated Traditional and Western Medicine Press and Springer-Verlag GmbH Germany, part of Springer Nature 2021

1. Department of Medicine, David Geffen School of Medicine, University of California Los Angeles, California, USA; 2. Center for East-West Medicine, Department of Medicine, David Geffen School of Medicine, University of California Los Angeles, California, USA

Correspondence to: Dr. Ka-Kit P. Hui, E-mail: khui@mednet. ucla.edu

DOI: https://doi.org/10.1007/s11655-021-3500-9 


\section{Goals and Implementation of Palliative Care}

Implicit in these definitions are the goals outlined by the WHO, which can be categorized into goals related to patient care, family involvement, and community and health care systems expansion.

Patient care goals include: (1) universal accessibility, (2) provision of care not only to the dying patient, but also to those with serious/life-threatening illnesses, or with physical, psychological, social or spiritual consequences of illness and its therapy, (3) emphasis on early diagnosis, assessment, and treatment of problems, (4) implementation of care early in the course of disease as an adjunct to other life-prolonging interventions or preventive measures, (5) relief of suffering in addition to anticipation and prevention of suffering, (6) enhancement of quality of life, dignity, and comfort, and improvement of the course of illness, (7) achievement of a comfort level consistent with the patient's goals without intentionally hastening death, (8) provision of guidance regarding optimal lifesustaining treatments and alternatives to life-prolonging therapies of questionable benefit near the end of life.

Family involvement goals include: (1) ongoing patient and family support throughout the illness, and (2) provision of support for bereaved family members after the patient's death to mitigate financial hardship resulting from the illness.

Community and health care systems expansion goals involve: (1) advancement of palliative care by all levels of health care workers, whether trained in basic, intermediate or specialized palliative care, (2) active involvement in the community including accessibility to palliative care in patients' homes and at all levels of health care systems, and (3) improvement in continuity of care leading to strengthening of the health care system. ${ }^{(8)}$

Palliative care is delivered by an interdisciplinary team of palliative care physicians, nurses, social workers, and others, who collaborate with the medical team, often described as "an extra layer of support." Indicated at any age and stage of serious illness, palliative therapies can be initiated at any time as an adjunct to curative or standard treatment. ${ }^{(9)}$

\section{Palliative Care Outcomes}

Palliative care implementation improves the quality equation and fulfills the triple aim outlined by the Institute for Healthcare Improvement by (1) improving patient experience (including quality of care and patient satisfaction), (2) improving population health, and (3) reducing healthcare costs. ${ }^{(10)}$ Specifically, the "three pillars" of palliative care: communication, collaboration, and coordination, facilitate (1) improved outcomes, (2) a reduced symptom burden, (3) care in accordance with patient and family preferences, (4) improved patient and family satisfaction, and (5) reduced costs. In this model care becomes longitudinal, rather than episodic, in keeping with the WHO goals. ${ }^{(11)}$

Studies show that integrating palliative care into oncology care improves patient satisfaction, ${ }^{(12)}$ lowers hospital admission costs ${ }^{(13,14)}$ and hospital readmissions, ${ }^{(15,16)}$ reduces chemotherapy costs, ${ }^{(17)}$ promotes adherence to end of life quality measures ${ }^{(18)}$ and decreases emergency department visits and hospital days. ${ }^{(19,20)}$ A 2010 randomized controlled trial (RCT) of 151 patients with newly diagnosed metastatic non-small cell lung cancer by Temel, et al ${ }^{(11)}$ demonstrated a potential survival benefit in the group assigned to early palliative care compared to usual care. ${ }^{(14)}$ In addition, there were lower chemotherapy related costs and no overall cost increases with the addition of palliative and hospice care..$^{(17,21)}$

\section{Integrative Medicine Definition}

Like palliative care, integrative medicine is a patient-centered, comprehensive, Iongitudinal approach to patient care. The Academic Consortium of Integrative Medicine and Health defines integrative medicine as an entity that "reaffirms the importance of the relationship between practitioner and patient, focuses on the whole person, is informed by evidence, and makes use of all appropriate therapeutic and lifestyle approaches, healthcare professionals and disciplines to achieve optimal health and healing". ${ }^{(22)}$

The Institute of Medicine 2009 Summit on Integrative Medicine and the Health of the Public further defined integrative medicine it as "a patientcentered comprehensive approach to health" that includes "physical, mental, emotional, and spiritual factors". It emphasizes prevention treatment rehabilitation, and recovery "using multiple modalities, both usual and unconventional, to manage, maintain and restore health" through the coordination of all phases of care "across the spectrum of caregivers 
and institutions".(23)

\section{Principles of Integrative Medicine}

Integrative medicine applies the biopsychosocial model proposed by George Engel ${ }^{(24)}$ in which multiple strata impact illness, from societal to molecular, with the patient's subjective experience playing an essential and ongoing role in diagnosis and management. It is a personalized approach to the patient that moves away from the reductionist model of disease described by Greene and Loscalzo, in which illness is broken down into its component parts (organs, tissue, cells or molecules). ${ }^{(25)}$ Hence, integrative medicine attempts to "put the patient back together" by focusing on the illness in the context of the whole person. The Modern Hippocratic Oath exemplifies this whole person approach: "I will remember that I do not treat a fever chart, a cancerous growth, but a sick human being, whose illness may affect the person's family and economic stability. My responsibility includes these related problems, if I am to care adequately for the sick."

\section{Integrative Medicine Modalities}

Integrative health modalities include (1) natural products (dietary supplements, botanicals, probiotics, vitamins and minerals), (2) mind-body modalities such as acupuncture, tai chi, qi gong, hypnotherapy, and relaxation techniques (breathing exercises, guided imagery, and progressive muscle relaxation) and (3) other established approaches such as (a) Ayurvedic medicine, (b) traditional Chinese medicine, (c) homeopathy (uses products derived from plants, minerals, or animals), (d) naturopathy (uses exercise, diet, massage), and (e) functional medicine (focuses on dynamic factors underlying the illness). ${ }^{(26,27)}$

These modalities are increasingly used in the United States. The National Center for Complementary and Integrative Health ranked the 10 most common integrative health modalities used by American adults in the 2012 National Health Interview Survey (NHIS) with the percentage of adults using each modality as follows: natural products $(17.7 \%)$, deep breathing $(10.9 \%)$, Yoga, tai chi, qi gong $(10.1 \%)$, chiropractic or osteopathic manipulation $(8.4 \%)$, meditation $(8.0 \%)$, massage $(6.9 \%)$, special diets $(3.0 \%)$, homeopathy $(2.2 \%)$, progressive relaxation $(2.1 \%)$, and guided imagery $(1.7 \%){ }^{(26)}$ Further growth of the use of integrative health practices nationally is evidenced in the 2017
NHIS in which $14.3 \%$ of US adults reported practicing yoga percent in 2017 and $14.2 \%$ practiced meditation compared to $9.3 \%$ and $4.1 \%$, respectively in $2012 .{ }^{(26)}$

\section{Integrative Palliative Care}

Integrative palliative care is an emerging discipline that has developed as a hybrid of integrative health and palliative care resulting from shared principles and goals of these models. Both provide individualized, person-centered care through a multidisciplinary team approach that seeks to optimizes quality of life and well-being, ameliorate physical, emotional, and spiritual suffering, and contextualize care concordant with patient and family wishes and goals. Both disciplines underscore the importance of initiating care early in the course of illness and continuing through all stages to encompass the entire lifespan. Integrative palliative care is unique in that uses distinct integrative therapies (including mind-body modalities, traditional Chinese medicine, Ayurveda, dietary supplements) to provide symptom management for palliative care patients who are dying or experiencing the sequela of serious illness and its treatment. ${ }^{(28,29)}$

\section{Challenges and Limitations of Current Palliative Care Model}

One challenge in implementing a palliative care model that is fully aligned with its core principles involves patient selection. There is current underuse of palliative care in patients early in the course of serious illness, with a larger emphasis on patients with severe life-threatening illness and those at the end of life. In its definition, the palliative care model proposes early implementation of care delivery; however, the WHO reports a lack of awareness among policymakers, health care professionals, and the general public about the goals and benefits of palliative care and misconceptions about target groups, including the perception that palliative care is limited to cancer patients or those in the last few weeks of life. ${ }^{(30)}$

An intrinsic limitation of the palliative care model is in its approach to and application of pharmacological therapies. Efforts are focused on providing supportive measures, emphasizing early recognition of symptoms and subsequent treatment with pharmacological therapy. Understanding the root (functional) cause of the symptoms and how to prevent symptom origination are not established methodologies used in the palliative care model. In addition, medications used in palliative 
care may suppress organ function, rather than restoring it. Current palliative care guidelines recommend the use of opioids, anticholinergics, antipsychotics, and benzodiazepines to provide symptom relief. ${ }^{(7)}$ These agents may lead to iatrogenic effects such as opioidinduced constipation, nausea, insomnia, and fatigue. A 2018 systematic review of 12 studies concluded there was little evidence regarding the effectiveness and safety of the drugs routinely used in palliative care in the dying patient. ${ }^{(31)}$

\section{East-West Integrative Palliative Care Model}

We propose an East-West integrative palliative care model based on our current East-West integrative medicine model that complements and expands the existing palliative and integrative palliative care approaches. Our model in its application to palliative care espouses the new emphasis on providing support to live well through the life course after initial diagnosis with a serious illness. In addition, we shift the paradigm of the palliative care model that involves suppressing symptoms of illness with drugs to addressing the functional cause of the symptoms and the imbalance and declining homeostatic reserve that perpetuate them. By using nonpharmacological therapy early in the course of illness, we attempt to alter the disease course by targeting the dysregulation that produces symptoms. ${ }^{(32-36)}$

Since its founding in 1993, the UCLA Center for East-West Medicine has been using an East-West medicine person-centered model that can be applied to palliative care patients. Using a person-centered, healing-oriented, integrative approach, we treat patients with serious refractory problems, including cancer patients at various stages of their journey. Beginning with managing the stress associated with a new cancer diagnosis, we continue to support patients through oncological therapies in order to limit longand short-term side effects and to maintain remission or slow disease progression. ${ }^{(36)}$ In our East-West integrative palliative care model, we focus not only on the last 6 months of life in seriously ill or terminal patients, but also on the entire lifespan of those coping with long-term consequences of diabetes, autoimmune diseases, chronic heart, lung, liver, kidney diseases, and now the sequelae of corona virus disease 2019 (COVID-19) infection. Congruent with the WHO goals for palliative care, by emphasizing palliation at all stages of the disease process, our model seeks to enhance quality of life.
Evaluation of each patient begins with a comprehensive history and physical examination. We probe into all aspects of the medical history including chronological medical illnesses, injuries, surgeries, family history, social habits, psychological/ emotional factors/stressors, sleep, diet, medications, and supplements. All of this data is synthesized to create a complex biopsychosocial portrait of the patient and to address each illness and stressor in the context of the whole person. Furthermore, we classify the characteristics into a Chinese medicine pattern diagnosis (for example, yin deficiency, blood stasis) that helps to identify deficiencies, excesses, and imbalances and creates a framework for treatment.

In our approach, beyond symptom amelioration, the primary goal of treatment is to re-regulate imbalances and replete deficiencies that lead to symptom appearance by turning on intrinsic healing mechanisms. Using acupuncture, diet, exercise, and stress management, our goal is to preserve digestive function, restorative sleep and mobility by shifting the symptomno symptom equation so as to prevent symptoms from arising. Acupuncture, as part of a comprehensive system of care, can be used in this re-regulating function.

Currently, there is growing evidence for use of acupuncture for symptom management in palliative care for 17 indications, though weak. ${ }^{(37)}$ Despite the absence of strong evidence, experts increasingly recommend the use of acupuncture for treatment of symptoms because of its safety profile. In cancer care, patients often present with symptom clusters of multiple co-occurring complaints (pain, fatigue, sleep disturbance) and acupuncture can be targeted to addressing the entire symptom cluster. At present, acupuncture is recommended in oncology care for pain, cancer-related fatigue, chemotherapy-related nausea and vomiting, possibly xerostomia, as well as palliative care and cancer survivorship. ${ }^{(38,39)}$ Current rigorous evidence for use of other integrative modalities in hospice and palliative care is lacking. More well-designed studies are needed to assess the effects of these therapies on the course of disease.

\section{Conclusion}

The discipline of palliative care is guided by the WHO fundamental principle of providing comprehensive, compassionate, person-centered care. It uses a biopsychosocial approach to provide 
longitudinal rather than episodic care, addressing physical, emotional, and spiritual suffering in seriously ill and dying patients. In current practice, this caremodel is underused in patients early in illness focusing on symptom suppression and amelioration of terminally ill and end-of-life patients through pharmacological therapy. Currently, there is little evidence regarding the effectiveness and safety of the drugs routinely used in palliative care in the dying patient, creating an opportunity to explore integrative palliative care, an emerging discipline that combines the philosophies of palliative care and integrative medicine to support patients in living well throughout their illness journey.

We have proposed an East-West integrative palliative care model based on our current EastWest person-centered model and the palliative care and integrative palliative care models using nonpharmacological therapy that shifts the paradigm from suppressing the symptoms of illness to addressing their underlying cause and the imbalance and declining homeostatic reserve that perpetuate them. Through acupuncture, diet, exercise, and stress management, we attempt to re-regulate imbalances and replete deficiencies that lead to symptom appearance by turning on intrinsic healing mechanisms. Extrapolating from palliative care studies, in the East-West integrative care model, we seek to (1) improve outcomes, (2) reduce symptom burden, (3) provide care in accordance with patient and family preferences, (4) improve patient and family satisfaction, and (5) reduce costs. ${ }^{(40)}$ This whole-person integrative model expands the reach of palliative care by not only relieving symptoms, but also preventing symptoms and improving function, allowing the patient to maintain as many activities as possible and prolonging a better quality of life. Through this approach we reframe the dialogue such that patients are "living better" rather than "dying better" when faced with serious illness or death.

\section{Conflict of Interest}

Author Hui KK is a member of the Editorial Board for CJIM. The paper was handled by the other editor and has undergone rigorous peer review process. Author Hui KK was not involved in the journal's review of, or decisions related to, this manuscript.

\section{Acknowledgements}

We would like to thank the Panda Charitable Foundation, the Gerald Oppenheimer Family Foundation and the Annenberg Foundation for their partial support in this work. We would also like to thank Vincent Tse for his help in the preparation of this manuscript.

\section{REFERENCES}

1. Carter R. Cicely Saunders-founder of the hospice movement: selected letters 1959-1999. J R Soc Med 2003;96:149-151.

2. History of hospice. In: NHPCO. Accessed on Mar 29, 2021. Available at: https://www.nhpco.org/hospice-care-overview/ history-of-hospice/.

3. Richmond C. Dame Cicely Saunders. BMJ 2005;331:238.

4. Center for Palliative Care. Accessed on Apr 30, 2021. Available at: https://pallcare.hms.harvard.edu/.

5. Morrison RS, Augustin R, Souvanna P, Meier DE. America's care of serious illness: a state-by-state report card on access to palliative care in our nation's hospitals. J Palliat Med 2011;14:1094-1096.

6. WHO Definition of Palliative Care/WHO Definition of palliative care for children. In: Geneva: World Health Organization. 2002 Accessed on Mar 29, 2021. Available at: http://www.who.int/cancer/palliative/definition/en/.

7. Clinical Practice Guidelines for Quality Palliative Care. 4th ed. In: National Consensus Project for Quality Palliative Care. 2018. Accessed on Apr 30, 2021. Available at: https:// www.nationalcoalitionhpc.org/ncp/.

8. Integrating palliative care and symptom relief into primary health care: a WHO guide for planners, implementers and managers. Geneva: World Health Organization; 2018. Available at: https://apps.who.int/iris/handle/10665/274559.

9. Kelley AS, Morrison RS. Palliative care for the seriously ill. N Engl J Med 2015;373:747-755.

10. Institute for Healthcare Improvement. In: Institute for Healthcare Improvement. Accessed on Apr 30, 2021. Available at: http://www.ihi.org:80/Engage/Initiatives/ TripleAim/Pages/default.aspx.

11. National Academies of Sciences, Engineering, and Medicine, Health and Medicine Division, Board on Health Sciences Policy, Board on Health Care Services, Roundtable on Quality Care for People with Serious IIIness. Models and strategies to integrate palliative care principles into care for people with serious illness: proceedings of a workshop. Washington (DC): National Academies Press (US); 2017. Available at: http://www.ncbi.nlm.nih.gov/books/NBK459050/.

12. El-Jawahri A, Greer JA, Temel JS. Does palliative care improve outcomes for patients with incurable illness? A review of the evidence. J Support Oncol 2011;9:87-94.

13. Morrison RS, Penrod JD, Cassel JB, Caust-Ellenbogen M, Litke A, Spragens $L$, et al. Cost savings associated with US hospital palliative care consultation programs. Arch Intern Med 2008;168:1783-1790.

14. Temel JS, Greer JA, Muzikansky A, Gallagher ER, Admane 
S, Jackson VA, et al. Early palliative care for patients with metastatic non-small-cell lung cancer. New Engl J Med 2010;363:733-742.

15. Adelson K, Paris J, Horton JR, Hernandez-Tellez L, Ricks D, Morrison RS, et al. Standardized criteria for palliative care consultation on a solid tumor oncology service reduces downstream health care use. J Oncol Pract 2017;13:e431-e440.

16. Enguidanos S, Vesper E, Lorenz K. 30-day readmissions among seriously ill older adults. J Palliat Med 2012;15:1356-1361.

17. Greer JA, Tramontano AC, McMahon PM, Pirl WF, Jackson VA, El-Jawahri A, et al. Cost analysis of a randomized trial of early palliative care in patients with metastatic nonsmallcell lung cancer. J Palliat Med 2016;19:842-848.

18. Ziegler LE, Craigs CL, West RM, Carder P, Hurlow A, Millares-Martin $\mathrm{P}$, et al. Is palliative care support associated with better quality end-of-life care indicators for patients with advanced cancer? A retrospective cohort study. BMJ Open 2018;8:e018284.

19. Brumley RD, Enguidanos S, Cherin DA. Effectiveness of a home-based palliative care program for end-of-life. J Palliat Med 2003;6:715-724.

20. Lustbader D, Mudra M, Romano C, Lukoski E, Chang A, Mittelberger $\mathrm{J}$, et al. The impact of a home-based palliative care program in an accountable care organization. $\mathrm{J}$ Palliat Med 2017;20:23-28.

21. Greer JA, Pirl WF, Jackson VA, Muzikansky A, Lennes IT, Heist RS, et al. Effect of early palliative care on chemotherapy use and end-of-life care in patients with metastatic non-smallcell lung cancer. J Clin Oncol 2012;30:394-400.

22. Academic consortium for integrative medicine and health: introduction. In: Academic Consortium for Integrative Medicine and Health. Accessed on Apr 30, 2021. Available at: https://imconsortium.org/about/introduction/.

23. Integrative Medicine and the Health of the Public: A summary of the February 2009 summit. National Academies Press (US); 2009. Available at: https://www.ncbi.nIm.nih. gov/books/NBK219637/.

24. Engel GL. The need for a new medical model: a challenge for biomedicine. Science 1977;196:129-136.

25. Greene JA, Loscalzo J. Putting the patient back togethersocial medicine, network medicine, and the limits of reductionism. N Engl J Med 2017;377:2493-2499.

26. Complementary, alternative, or integrative health: what's in a name? In: NCCIH: National Center for Complementary and Integrative Health. 2021. Accessed on Apr 30, 2021. Available at: https://www.nccih.nih.gov/health/complementaryalternative-or-integrative-health-whats-in-a-name.

27. Homeopathy: what you need to know. In: NCClH: National Center for Complementary and Integrative Health. 2021. Accessed on Apr 30, 2021. Available at: https://www.nccih. nih.gov/health/homeopathy.

28. Adler SR, Marchand LR, Heap N. Integrative palliative care: enhancing the natural synergy between integrative health and palliative medicine. J Altern Complement Med N Y N 2019;25:257-259.

29. Chiaramonte DR, Adler SR. Integrative palliative care: a new transformative field to alleviate suffering. J Altern Complement Med N Y N 2020;26:761-765.

30. Palliative care fact sheet. Accessed on Apr 30, 2021. Available at: https://www.who.int/news-room/fact-sheets/ detail/palliative-care.

31. Jansen K, Haugen DF, Pont L, Ruths S. Safety and effectiveness of palliative drug treatment in the last days of life-a systematic literature review. J Pain Symptom Manage 2018;55:508-521.e3.

32. Hui KK. The potential for incorporating traditional Chinese medicine into clinical practice. Traditional medicine: better science, policy and services for health development, Proceedings of a WHO international symposium. Japan, 2001.

33. Pritzker S, Katz M, Hui KK. Person-centered medicine at the intersection of East and West. Eur J Pers Center Health 2013;1:209-215.

34. Hui KK, Li ZL. The University of California at Los Angeles Center for East-West medicine's patient-centered integrative East-West medical approach. Chin J Integr Tradit West Med (Chin) 2018;38:484.

35. Wu XQ, Hui KK. Progress in scientific research bridging traditional Chinese and modern medicine in the UCLACEWM clinical model. Chin J Integr Tradit West Med (Chin) 2019;39:1500-1505.

36. Hui KK, Hui EK, Johnston MF. The potential of a personcentered approach in caring for patients with cancer: a perspective from the UCLA center for East-West medicine. Integr Cancer Ther 2006;5:56-62.

37. Birch S, Bovey M, Alraek T, Robinson N, Kim TH, Lee MS. Acupuncture as a treatment within integrative health for palliative care: a brief narrative review of evidence and recommendations. J Altern Complement Med N Y N 2020;26:784-791.

38. Miaskowski C, Barsevick A, Berger A, Casagrande R, Grady $\mathrm{PA}$, Jacobsen $\mathrm{P}$, et al. Advancing symptom science through symptom cluster research: expert panel proceedings and recommendations. J Natl Cancer Inst 2017;109.

39. Huang T, Hung T, Kim S, Hui K. Acupuncture for management of symptom clusters in a patient with metastatic breast cancer: a case report. OBM Integr Complement Med 2020;5:1-6.

40. Balboni TA, Hui KP, Kamal AH. Supportive care in lung cancer: improving value in the era of modern therapies. Am Soc Clin Oncol Educ Book 2018;38:716-725.

(Accepted August 6, 2021) Edited by WANG Wei-xia 